\title{
Desenvolvimento local e conservação: o caso do município de Ubatuba, São Paulo (BR)
}

\author{
Kelly Cristina de Melo ${ }^{(a)}$ \\ (a) Laboratório de Climatologia e Biogeografia, Departamento de Geografia, Universidade de São Paulo, \\ Brasil, kelly.melo@usp.br
}

\section{EIXO: BIOGEOGRAFIA, MANEJO DE ÁREAS NATURAIS E PROTEGIDAS: CONSERVAÇÃO DA BIODIVERSIDADE}

\begin{abstract}
Resumo
O litoral norte do Estado de São Paulo caracterizou-se como uma região marginal às grandes cidades paulistas até meados da década de 1970, acarretando, durante este período, estagnação econômica de seus municípios, mas também manutenção de seu patrimônio natural. Se por um lado a diversidade do ambiente mantém uma paisagem litorânea única, por outro gera grande complexidade no uso e ocupação da terra. Por meio de uma abordagem integrada da paisagem buscou-se compor um cenário de síntese para compreensão da organização socioespacial. A pesquisa foi desenvolvida por meio de pesquisa bibliográfica, levantamentos de campo e análises sobre as principais características e atributos do meio. Ressalta-se que as políticas públicas destinadas a conservação da biodiversidade não incluíram em seu escopo medidas de proteção às comunidades tradicionais, ou mesmo à população local de uma maneira geral, permitindo a contínua descaracterização dos hábitos, tradições e modos de vida.
\end{abstract}

Palavras chave: Ubatuba; Unidades de Conservação; Patrimônio Natural; Paisagem.

\section{Introdução}

O município de Ubatuba está localizado no Litoral Norte do Estado de São Paulo (Figura 1). A população local é de 78.801 habitantes (IBGE, 2010) com uma população flutuante de cerca de 300 mil pessoas em épocas de alta temporada (dezembro a março).

Ubatuba possui forma alongada, com eixo maior posicionado na direção sudeste-nordeste com cerca de $60 \mathrm{~km}$ de extensão, no sentido transversal a largura do município varia entre 5 e $17 \mathrm{~km}$, aproximadamente, junto ao oceano o perímetro é bastante recortado definindo uma extensa linha de contato com o mar, com baías, enseadas, pontões e costões, cuja extensão, considerando saliências e reentrâncias, é de cerca de 140 km, abrigando praias diversificadas (IPT, 1991).

A área de estudo foi escolhida por apresentar em suas paisagens diferentes temporalidades, apresentando setores urbanos e rurais, que ainda preservam modos de vida diferenciados, como caiçaras e quilombolas. Com a chegada da sociedade urbano-industrial as interferências nestas comunidades vieram atreladas às necessidades materiais e de acumulação capitalista, diferentes das que ali existiam. Esta interferência externa resultou em um espaço, hoje, apropriado pela urbanização e seus equipamentos, com drásticas reduções de ambientes originais, antes 
XVII Simpósio Brasileiro

de Geografia Fisica Aplicada

I Congresso Nacional

de Geografia Física
OS DESAFIOS DA GEOGRAFIA FÍSICA NA FRONTEIRA DO CONHECIMENTO

Instituto de Geociências - Unicamp

Campinas - SP

28 de Junho à 02 de Julho de 2017

preservados. Diante disso, o poder público, na figura do governo estadual, definiu a necessidade de que os remanescentes de florestas atlânticas e ecossistemas associados fossem transformados em Unidade de Conservação (UCs), como único recurso à sua manutenção em meio a áreas devastadas e degradadas pela expansão do mercado imobiliário.

O litoral norte de São Paulo caracterizou-se como uma região marginal às grandes cidades do planalto paulista até meados da década de 1970, acarretando em estagnação econômica, mas que manteve grande parte de seu patrimônio natural preservado. Se por um lado, a diversidade de sua paisagem condiciona a criação de uma paisagem litorânea única, por outro gera uma grande complexidade no processo de ocupação e organização do espaço, possuindo diferentes ambientes que condicionaram distintos processos de ocupação e transformação.

\section{Ubatuba: uso e ocupação}

Ate a década de 1960, o parcelamento do solo urbano restringia-se a pequenos loteamentos destinados à população local. A abertura de grandes loteamentos para empreendimentos turísticos iniciou-se no município na década de 1950 (LUCHIARI, 2000). Quando a ligação rodoviária é concluída, o turismo passa a ser a principal atividade econômica do município.

Em relação à atração turística, a proximidade da orla é o principal elemento para a valorização dos terrenos, não somente pela facilidade de locomoção à praia, mas por fornecer ao proprietário o status da garantia da propriedade do elemento cênico que é o mar.

Os municípios do Litoral Norte ainda apresentam como diferencial ao restante do litoral paulista, a concentração de residências de altíssimo padrão. No trecho de 210 km entre Guarujá e Ubatuba, existem algumas dezenas de propriedades com valor acima de 2,5 milhões de reais; construídas em meio a cenários naturais essas casas são símbolos de poder e riqueza à beira-mar. É importante ressaltar que quanto mais isolados dos fluxos urbanos forem, mais aumenta o valor agregado das residências. Desta forma, observamos que a legislação de uso do solo pode colaborar para consolidação das diferenças sociais relacionados ao uso e ocupação.

Há ainda neste cenário, a pressão do setor imobiliário junto às comunidades tradicionais residuais que detém o título de posse de áreas junto às praias, para que os vendam, criando uma situação de conflito. O processo de favelização é outro problema urbano comum a quase todos os municípios litorâneos, pois as populações marginalizadas alojam-se em áreas de proteção ambiental, de alto risco de ocupação ou insalubres, como as encostas de alta declividade da Serra do Mar e os manguezais. 


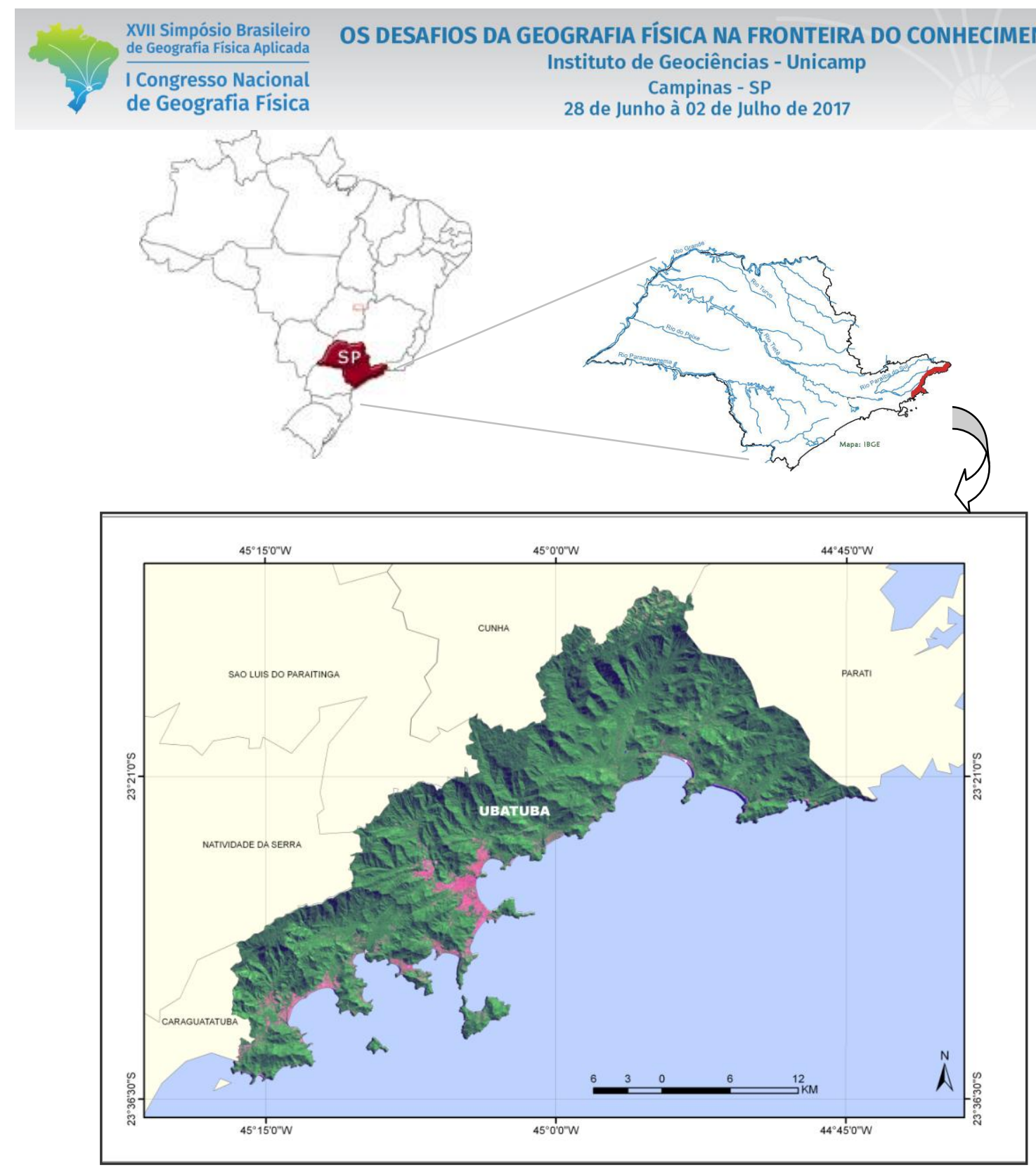

Figura 1 - Localização da área de estudo. Organização: Kelly C. Melo, 2010.

A entrada de turistas, provenientes dos centros urbanos, em direção ao litoral provoca, nestas áreas, o movimento de grandes valores financeiros, assim o desenvolvimento do turismo é visto pelos administradores como uma possibilidade viável de amenização dos problemas econômicos e sociais que afligem a região, mas acaba se transformando em fator de degradação dos recursos naturais e socioculturais que, quando recuperáveis, tem sua regeneração por meio de procedimentos demorados e custos socioeconômicos elevados.

No início da década de 1970 com a conclusão da rodovia BR 101 o atrativo turístico para o município de Ubatuba, que até esse período desenvolvia-se de maneira reduzida, ganhou impulso. Em consequência, houve grande expansão urbana, movida pelo setor imobiliário. Segundo Marcilio (2005) a maior parte das roças, fazendas e moradias da antiga Ubatuba localizavam-se em suas praias, chegando aos sertões apenas no decorrer do século XVIII. 
XVII Simpósio Brasileiro

de Geografia Fisica Aplicada

I Congresso Nacional

de Geografia Física
OS DESAFIOS DA GEOGRAFIA FÍSICA NA FRONTEIRA DO CONHECIMENTO

Instituto de Geociências - Unicamp

Campinas - SP

28 de Junho à 02 de Julho de 2017

O município passou então a se caracterizar como um pólo de atração de mão-de-obra principalmente para a construção civil motivada pelo setor turístico que promoveu uma interiorização da população local e ocupação de áreas mais distantes, afastadas da costa, frequentemente em setores de encosta.

Ubatuba congrega em seu território diferentes funções (PANIZZA, 2004): as ligadas ao turismo, relacionadas às residências de veraneio, ou segunda residência, assim como a preservação, com a presença do Parque Estadual da Serra do Mar (PESM). Entretanto, estes usos e funções se desenvolvem sem um planejamento adequado que estabeleça os interesses prioritários da sociedade, principalmente das comunidades locais e que com ela seja compartilhado.

O PESM, em Ubatuba, representa cerca de $80 \%$ da área do município e acaba sendo o grande limitador às instalações de loteamentos. Outros diplomas legais, notadamente o Decreto 750/93 ${ }^{1}$ da Mata Atlântica, que impede corte dessa floresta em estágios inicial, médio ou avançado, também coíbe a instalação de loteamentos em áreas menos urbanizadas.

A tabela 1 apresenta algumas das áreas e unidades de proteção inseridas nos limites do município, total ou parcialmente, as bases legais que as sustentam, a área em hectares e também o órgão público responsável.

Ubatuba cresceu, em termos de ocupação, a partir do centro histórico que se localiza na orla, neste processo, ocorre o progressivo englobamento de terrenos vizinhos à área central pelo surgimento de loteamentos para residências de veraneio até chegar a atual configuração com a presença de bairros periféricos.

A partir do cenário encontrado em Ubatuba, Panizza (2004) estabeleceu uma tipologia de conflitos e incompatibilidades de uso e ocupação do espaço, fundamentada na determinação dos setores funcionais, a conservação/preservação e o turismo/ocupação de residência secundária.

A incompatibilidade se concentra, sobretudo, na figura do PESM e nas residências secundárias e dois tipos de conflitos são recorrentes, o primeiro são as vias de acesso precárias e as frentes de ocupação constituídas pelas residências secundárias ou principais e o segundo é a poluição hídrica agravada pelas carências de infraestrutura de saneamento básico associadas ao aumento de frequência turística, que levaria para os rios e praias a contaminação das águas pelo esgoto doméstico. Esses conflitos trariam repercussões negativas à população local e temporária, para o meio natural e o turismo.

\footnotetext{
${ }^{1}$ DECRETO № 750, de 10 de fevereiro de 1993. Dispõe sobre o corte, a exploração e a supressão de vegetação primária ou nos estágios avançado e médio de regeneração de Mata Atlântica.
} 
XVII Simpósio Brasileiro de Geografia Fisica Aplicada

I Congresso Nacional de Geografia Física
OS DESAFIOS DA GEOGRAFIA FÍSICA NA FRONTEIRA DO CONHECIMENTO

Instituto de Geociências - Unicamp

Campinas - SP

28 de Junho à 02 de Julho de 2017

Tabela 1- Áreas legalmente protegidas - Ubatuba - SP. Fonte: São Paulo, 1996.

\begin{tabular}{|c|c|c|c|}
\hline Unidades e área & Proteção legal & $\begin{array}{l}\text { Área aproximada } \\
\text { (ha) }\end{array}$ & Responsabilidade \\
\hline $\begin{array}{l}\text { Parque Nacional da Serra } \\
\text { da Bocaina }\end{array}$ & $\begin{array}{l}\text { Decretos federais } \\
68172 / 71 ; 70694 / 72\end{array}$ & 100.000 & ICMBio \\
\hline $\begin{array}{l}\text { Parque Estadual da Serra } \\
\text { do Mar }\end{array}$ & $\begin{array}{l}\text { Decretos estaduais } \\
10251 / 77 ; 13313 / 79\end{array}$ & 315.000 & Fundação Florestal \\
\hline $\begin{array}{l}\text { Parque Estadual da Ilha } \\
\text { Anchieta }\end{array}$ & $\begin{array}{l}\text { Decreto estadual } \\
9629 / 77\end{array}$ & 828 & Fundação Florestal \\
\hline $\begin{array}{l}\text { Tombamento da Serra do } \\
\text { Mar }\end{array}$ & $\begin{array}{l}\text { Resolução estadual } \\
40 / 1985\end{array}$ & 1.300 .000 & CONDEPHAAT \\
\hline $\begin{array}{l}\text { Tombamento da Vila de } \\
\text { Picinguaba }\end{array}$ & $\begin{array}{l}\text { Resolução estadual } \\
7 / 1983\end{array}$ & 176,27 & CONDEPHAAT \\
\hline $\begin{array}{l}\text { Área indígena Boa Vista } \\
\text { do Sertão do Promirim }\end{array}$ & $\begin{array}{l}\text { Decreto federal } \\
94220 / 87\end{array}$ & 920,66 & FUNAI \\
\hline $\begin{array}{l}\text { Estação } \\
\text { Tupinambás }\end{array}$ & $\begin{array}{l}\text { Decreto federal } \\
94656 / 87\end{array}$ & 31,25 & ICMBio \\
\hline
\end{tabular}

O crescimento urbano tem sido caracterizado pela expansão irregular da periferia com pouca obediência à regulamentação urbana relacionada com a Lei de Uso e Ocupação do Solo (Lei n ${ }^{\circ}$ 711/84) e normas especificas para loteamentos. A ocupação irregular atinge a zona de amortecimento do PESM e em alguns bairros até áreas internas da UC.

Apesar de ter fortalecido a sede do município e impulsionado o crescimento, o turismo acabou por descaracterizar as antigas formas de ocupação, caracterizada por núcleos isolados no interior com atividade agrícola e nas praias por pequenas casas de pescadores. Em consequência ocorreu a interiorização da população local, com isso tem crescido a ocupação das encostas da Serra do Mar e morros associados, inclusive por favelas (SILVA, 1995).

O Litoral Norte, como um todo, constitui-se por ser extremamente suscetível aos conflitos de competência entre os entes federativos, em razão dos diversos tipos de uso existentes, no caso especifico de Ubatuba, por abrigar em seus limites um setor do PESM, de acordo com o Decreto Estadual 10.251/77, alterado pelo Decreto $n^{\circ} 13.313 / 79$, ao qual declara a Serra do Mar como de Área de Proteção Ambiental, restringindo o uso e a ocupação do solo, além da Resolução no 40/85, da Secretaria de Cultura do Estado de São Paulo, por meio do Conselho do Patrimônio Histórico e Artístico Nacional - CONDEPHAAT, que criou o tombamento da Serra do Mar. O fato de localizar-se no litoral do Estado de São Paulo inclui Ubatuba no espaço territorial submetido a regime especial de proteção, segundo o art. $225, \S 4^{\circ}$ da Constituição Federal, que trata da costa brasileira.

Observa-se assim que, para o controle e fiscalização do uso e ocupação do solo em Ubatuba, existem inúmeros órgãos públicos, estaduais e federais, envolvidos no controle e fiscalização da 
XVII Simpósio Brasileiro

de Geografia Fisica Aplicada

I Congresso Nacional

de Geografia Física
OS DESAFIOS DA GEOGRAFIA FÍSICA NA FRONTEIRA DO CONHECIMENTO

Instituto de Geociências - Unicamp

Campinas - SP

28 de Junho à 02 de Julho de 2017

ocupação do solo, tais como o CONDEPHAAT, o Departamento Estadual de Proteção de Recursos Naturais - DEPRN, o Instituto Chico Mendes de Conservação da Biodiversidade (ICMbio), e o Instituto Florestal - IF, além do controle por parte da poder público municipal, que deve verificar se a ocupação e o uso estão de acordo com o Plano Diretor (PD) de Ubatuba (Lei Municipal n 711 de 14/02/1984), revisto e ampliado pela Lei 2892 de 15 de dezembro de 2006.

\section{Bacias hidrográficas}

$\mathrm{Na}$ área de estudo, especificamente, a conformação das bacias hidrográficas é um importante fator a ser observado, influenciando as formas de uso e ocupação, pois os divisores das bacias exerceram papel importante na organização/isolamento relativo de cada comunidade (RAIMUNDO, 2001).

$\mathrm{Na}$ investigação realizada, buscando a compreensão das relações da sociedade e da natureza e as marcas que essas relações legaram à paisagem, foi utilizado um recorte em nível local, adotando sub-bacias hidrográficas representativas de características locais importantes para compreensão da realidade existente na área de estudo. Optou-se por discutir a situação de quatro sub-bacias possibilitando, assim, um olhar integrador em que os fatores naturais e os aspectos socioeconômicos se apresentassem dispostos numa perspectiva sistêmica, explicando os arranjos espaciais atuais.

\subsection{Sub-bacias hidrográficas}

Com intuito de detalhar as características da paisagem do município, adotou-se o recorte de 04 subbacias, duas localizadas ao norte (Fazenda-Bicas e Puruba-Quiririm) e duas localizadas no centrosul (Grande e Maranduba-Arariba).

\subsubsection{Sub-bacias do setor sul}

Dentro deste recorte que foi denominado de Setor Sul foram consideradas as sub-bacias do rio Grande e do rio Maranduba, principais expoentes no processo de ocupação, urbanização e uso turístico de Ubatuba. A sub-bacia do rio Grande é composta pelos cursos d'água que partem das porções mais elevadas da Serra do Mar e drenam em direção ao Oceano Atlântico, compreendendo as áreas de drenagens dos rios Grande, da Lagoa e Acaraú (Figura 2). Essas drenagens perfazem $102,6 \mathrm{~km}^{2}$ (IPT, 2000). Esta é a segunda maior bacia em volume de água no município de Ubatuba, menor apenas que sub-bacia Quiririm-Puruba, situada na parte norte do município que possui área de $166,4 \mathrm{~km}^{2}$. 


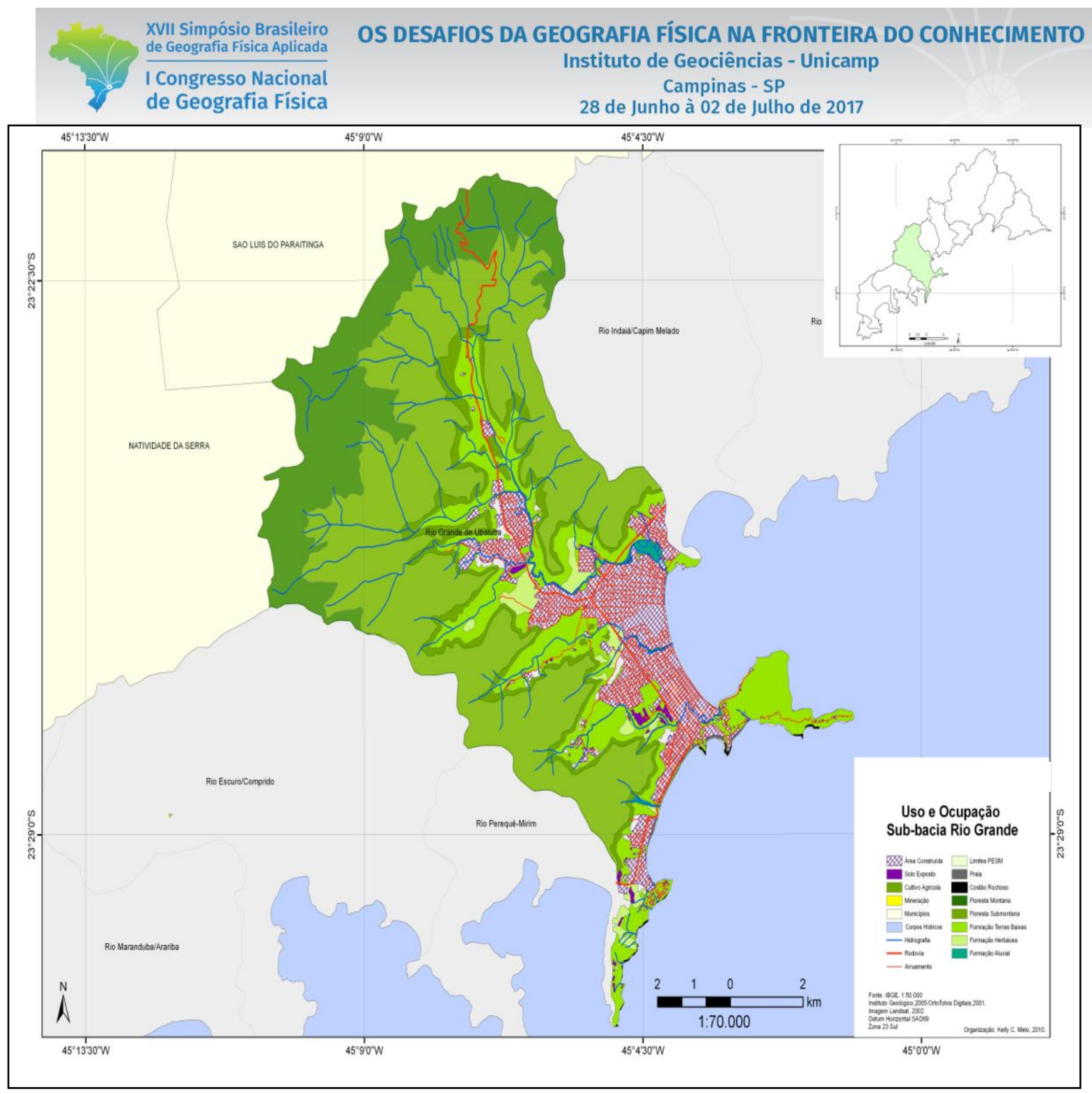

Figura 2 - Sub-bacia Rio Grande. Organização: Kelly C. Melo, 2010.

Entre a cota 100m e 400m existe um aglomerado com características predominantemente urbanas, mas que traz aspectos rurais em alguns setores. O uso predominante da área é para moradia, porém um grande número de casas é usado para lazer. O uso com agricultura de subsistência e criação de animais representa apenas 13\% das áreas ocupadas (IPT, 2000).

A área abrangida pela bacia não é atendida em sua totalidade por serviços públicos como coleta de lixo, energia elétrica, manutenção de sistema viário e saneamento básico (coleta de esgoto e distribuição de água). O maior conflito do uso da água nesta bacia é com relação à ocupação do solo. Cabe destacar que o manancial do Rio Grande tem todas as nascentes e a foz dentro do limite territorial do município de Ubatuba, não havendo disputas de água com outros municípios. Além disso, acima da captação da água não existem centros industriais ou grandes áreas agrícolas que poderiam potencializar o risco de degradação do manancial (BUCHIANERI, 2004).

A sub-bacia do rio Maranduba, possui $67,7 \mathrm{~km}^{2}$ e assim como a sub-bacia do rio Grande, é um setor amplamente urbanizado, com a área mais próxima ao mar ocupada por equipamentos de 
hospedagem e casas de veraneio. As características físicas também são semelhantes, pois ocupam um setor entre a serrania Costeira e as Baixadas Litorâneas.

A Figura 3 apresenta o uso e ocupação nesta sub-bacia. A praia da Maranduba é uma das mais frequentadas no município, pois apresenta concentração de serviços que atraem os turistas (bares, restaurantes, quiosques, etc.). O setor mais afastado da orla, chamado de sertão, concentra uma população local de baixa renda, com residências improvisadas, em condições insalubres para moradia, além de precária infraestrutura, assim como pequenos cultivos agrícolas sendo denominado de Sertão do Quina

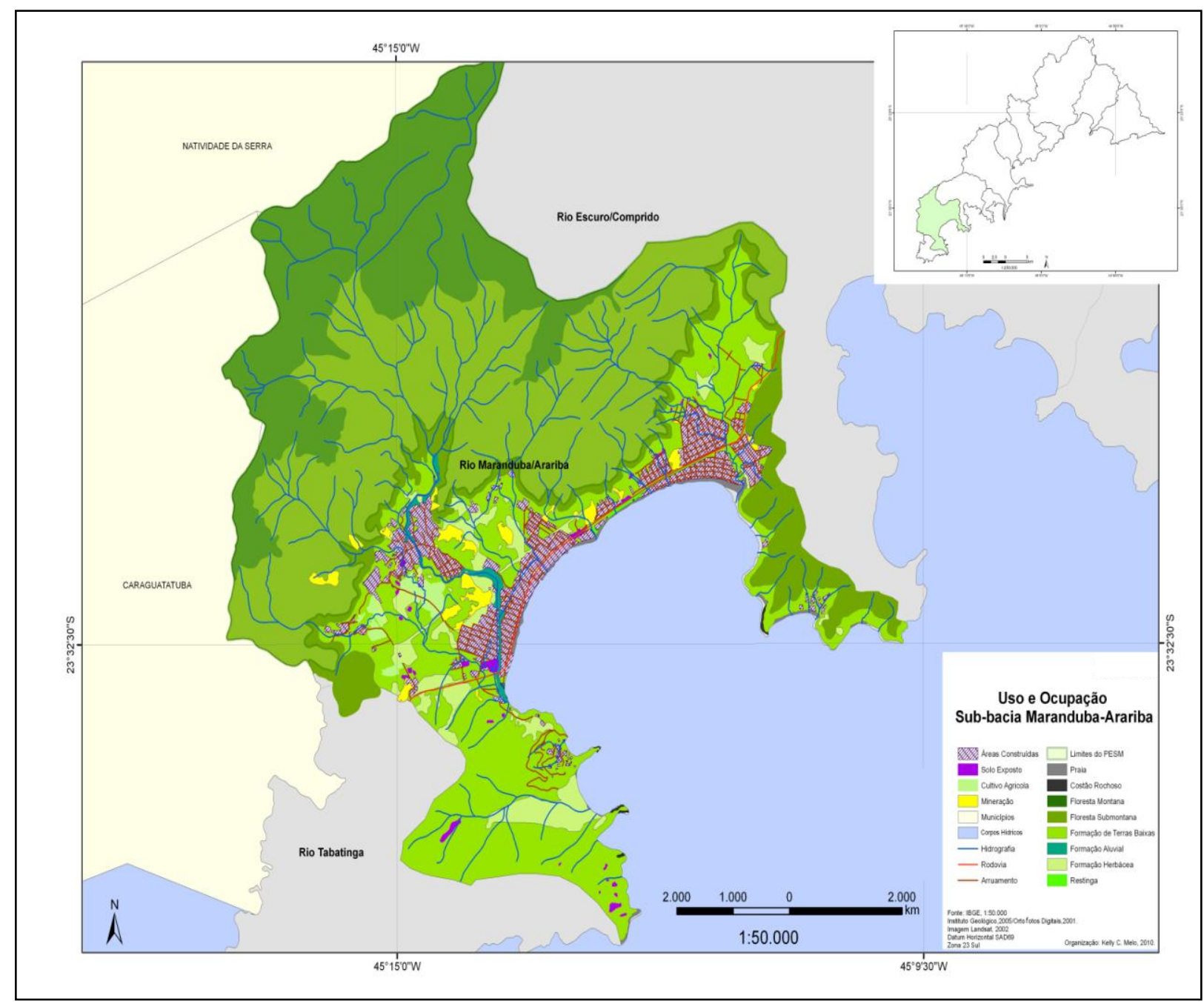

Figura 3 - Sub-bacia Maranduba-Arariba. Organização: Kelly C. Melo, 2010.

\subsubsection{Sub-bacias do setor norte}

Dentro deste recorte denominado de Setor Norte, são consideradas as sub-bacias do rio Fazenda e do rio Puruba, evidenciando áreas no município de Ubatuba que ainda preservam sua vegetação, pela ocupação por comunidades tradicionais e também pela presença do PESM. A bacia hidrográfica do rio Fazenda, com 80,1 km², está totalmente inserida nos limites do PESM. 
Apresenta-se com uso de pequenas posses, cujos habitantes praticam agricultura anual no sistema de coivara e extração de recursos naturais nas áreas florestadas. A Figura 4 traz o uso e ocupação do solo nesta sub-bacia.

As características encontradas no setor norte de Ubatuba são muito peculiares, distinguindo-o dos demais setores do litoral paulista. Vertentes escarpadas da Serra do Mar cobertas pela floresta ombrófila densa, ravinas que evidenciam os movimentos de massa, maciços isolados, esporões que adentram ao mar formando pequenas enseadas, baixadas recortadas por rios de baixa hidrodinâmica e que recebem influência das marés oceânicas proporcionando a existência dos manguezais, que se encontram com faixa de restingas e praias arenosas.

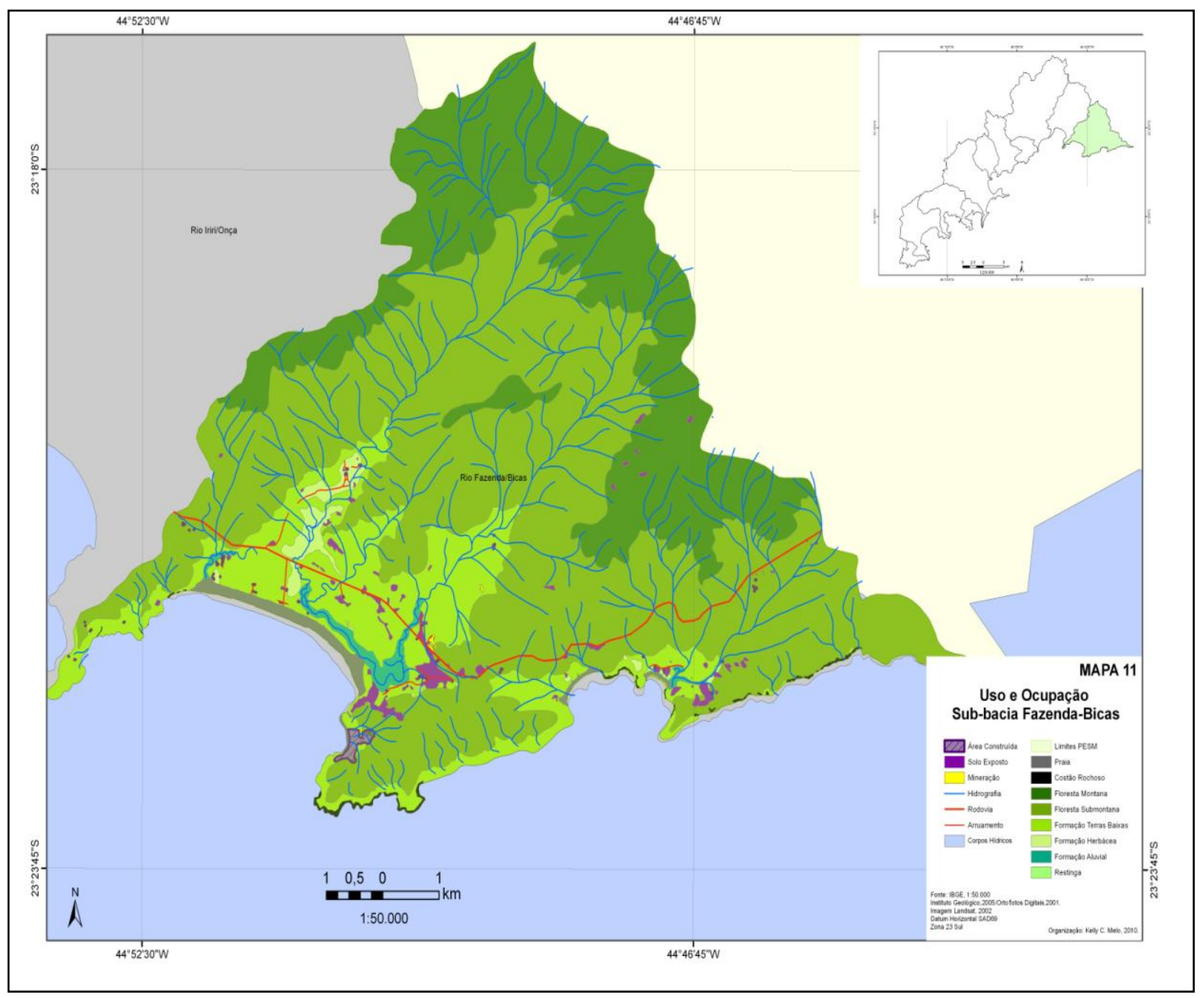

Figura 4 - Sub-bacia Faxenda-Bicas. Organização: Kelly C. Melo, 2010.

A bacia hidrográfica do Rio Puruba, por sua vez, possui área de $166,4 \mathrm{~km}^{2}$ e o limite com o PESM é a cota $100 \mathrm{~m}$, na Serra do Mar, desta forma, parte da comunidade está assentada fora dos limites da UC, principalmente na planície costeira e contato desta com a serra e parte está instalada dentro dos limites do PESM já nos contrafortes da Serra do Mar. A Figura 5 traz o uso e ocupação do solo nesta sub-bacia. 
O turismo ainda é incipiente no Sertão de Puruba, contudo já se observa a instalação de chácaras de finais de semana, assim como a visitação aleatória por grupos não organizados, principalmente nas cachoeiras e trilhas. Há o uso predominante de culturas de banana, uso corrente desde a década de 1940 (RAIMUNDO, 2007), sendo este sertão considerado como um dos últimos remanescentes de função agrícola no município de Ubatuba, já que nas demais localidades percebe-se um intenso processo de mudanças em função: de práticas tradicionais agrícolas pra uso turístico.

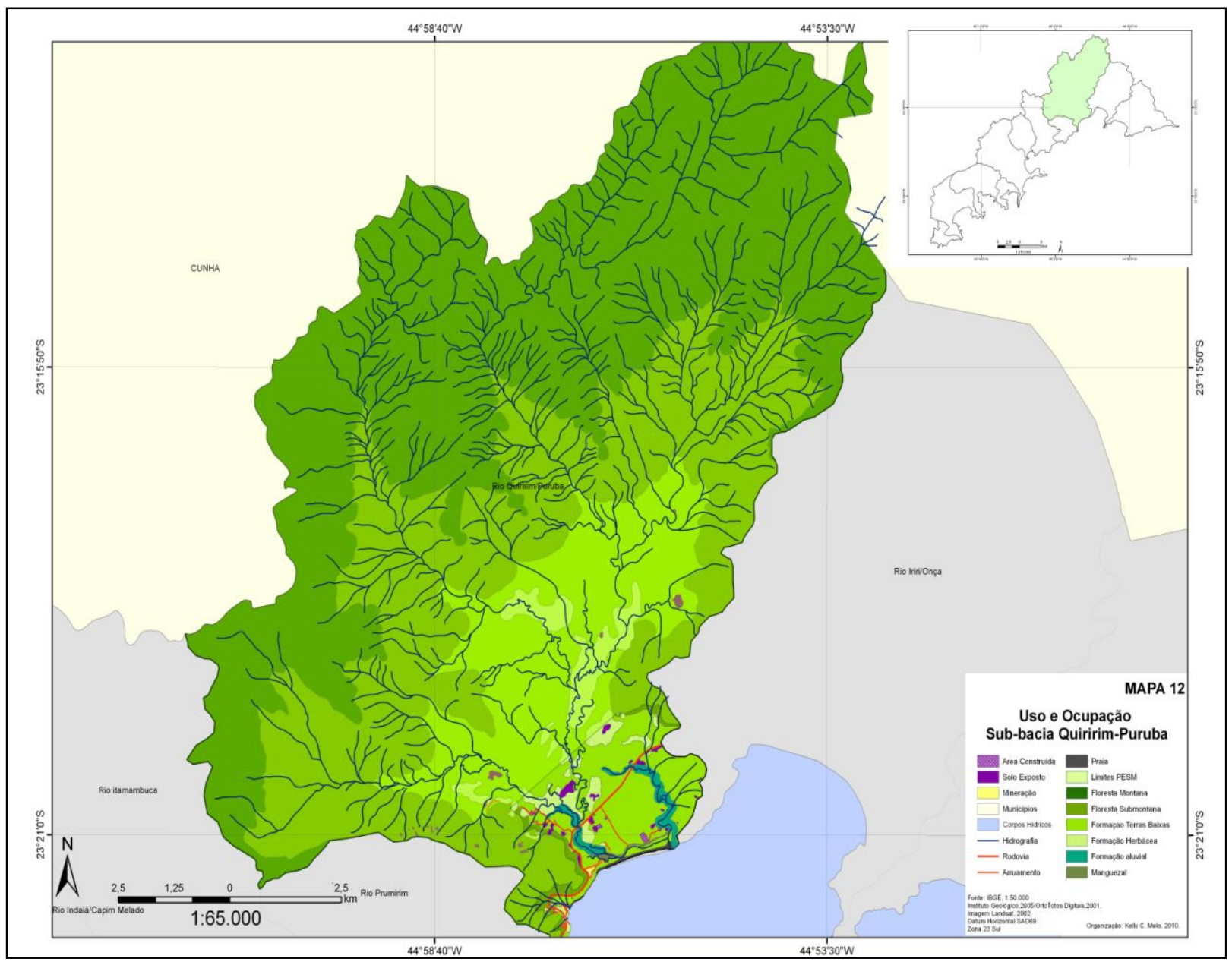

Figura 5 - Sub-bacia Quiririm-Puruba. Organização: Kelly C. Melo, 2010.

A orla desse setor tem passado por processos mais intensos que o sertão em relação à transformação ligada ao turismo principalmente com o comércio de lotes. Percebe-se a instalação de segunda residência, assim como de equipamentos de hospedagem. Importante destacar que há traços socioculturais fortes e singulares nas comunidades situadas neste setor norte de Ubatuba. A Vila de Picinguaba é uma referência como vila de pescadores e a comunidade de Camburi, como Quilombolas. 


\section{Considerações Finais}

As atividades econômicas do Litoral Norte estão fundamentalmente ligadas aos recursos naturais existentes, a cobertura vegetal das áreas montanhosas, o substrato geológico na extração mineral, qualidade visual da área litorânea, entre outros fatores que delegam à região o papel de centro turístico, valorizando a especulação imobiliária e setores sociais privilegiados economicamente, entretanto, este cenário impõe a contínua expropriação da população local, principalmente aquela reconhecida como tradicional e o desarranjo dos seus atributos geoecológicos.

A paisagem de Ubatuba apresenta um mosaico, onde se pode perceber uma singularidade própria, refletindo condições socioeconômicas e geoecológicas atuais, que conservam ainda características de tempos pretéritos por meio dos agentes construtores daquela paisagem, como os caiçaras e quilombolas, por exemplo, e também o poder público com a construção de acessos rodoviários, o setor imobiliário e as segundas residências de veranistas.

O planejamento das diversas formas de uso e ocupação do solo e a sua racionalização deve basearse em considerações socioeconômicas e também na análise das características ambientais. A investigação de tais características é realizada visando harmonizar a integração entre as atividades humanas e o meio ambiente.

A ocupação como se dá agora é caracterizada pela supressão da biodiversidade, decorrente da degradação dos recursos naturais, principalmente os recursos hídricos, impacto relacionado diretamente com as ocupações irregulares e a falta de saneamento básico, além disso, continuando a ocupação da forma atual, haverá um deslocamento ocupacional para setores cada vez menos apropriados, revertendo-se em prejuízo social, econômico e ecológico.

Esperamos que a pesquisa apresentada possa contribuir para a elaboração de trabalhos integrados, com perspectivas de aprofundar o conceito de paisagem, assim como destacar a importância da preservação dos atributos paisagísticos de Ubatuba, e por consequiência de todo o Litoral Norte paulista, detentor de rara beleza cênica, relações sociais e manifestações da cultura material e imaterial impares ao território paulista.

\section{Bibliografia}

ADAMS, C. Caiçaras na mata atlântica: pesquisas científicas versus planejamento e gestão ambiental. São Paulo, Ed. Annablume: Fapesp. 336p. 2000.

BUCHIANERI, V.C. Geração da serie histórica de vazão por meio do Modelo SMAP, subsídio para o plano de manejo da bacia do rio Grande de Ubatuba. Dissertação. ESALQ. Piracicaba. 2004

INSTITUTO BRASILEIRO DE GEOGRAFIA E ESTATÍSTICA. Cidades - Ubatuba. Disponível em http://www.cidades.ibge.gov.br/ acesso em 15/01/17. 
INSTITUTO DE PESQUISAS TECNOLÓGICAS. Carta Geotécnica do Município de Ubatuba, SP. São Paulo. IPT-IG. 1991.

Diagnóstico da situação atual dos recursos hídricos da unidade de gerenciamento dos recursos hídricos do Litoral Norte. (CD). Ubatuba, Comitê de bacias hidrográficas do Litoral Norte, 2000.

Plano de gerenciamento de recursos hídricos do Litoral Norte (CD). Ubatuba, Comitê de bacias hidrográficas do Litoral Norte, 2001.

LUCHIARI, M.T Turismo, natureza e cultura caiçara: um novo colonialismo? In: Serrano, C \& Bruhns, H (org). Viagens à natureza: turismo, cultura e ambiente. Campinas. Ed. Papirus, p 59-84. 1998.

O lugar no mundo contemporâneo: turismo e urbanização em Ubatuba - SP. Tese de Doutorado. IFCH - UNICAMP, São Paulo. 2000.

PANIZZA, A. C. Imagens orbitais, cartas e coremas: uma proposta metodológica para o estudo da organização e dinâmica espacial: aplicação ao município de Ubatuba, Litoral Norte, Estado de São Paulo, Brasil. 2004. 302f. Tese (Doutorado em Geografia), F.F.L.C.H., Universidade de São Paulo, São Paulo, 2004. Disponível:

PICCOLO, P.R. Ensaio Metodológico sobre a ocupação humana e as transformações no mosaico ambiental na fazenda da Picinguaba, SP (PESM) nos períodos de 1962 e 1990. Dissertação de Mestrado, Rio Claro, Instituto de Geociências e Ciências Exatas, UNESP. 1992.

SILVA, A.C. O Litoral Norte do estado de São Paulo (formação de uma região periférica). Tese de doutorado. FFLCH-USP, São Paulo. 1975.

SILVA, F. L. M. O risco geológico associado à ocupação de áreas de mineração no município de Ubatuba (SP). Dissertação de Mestrado. Instituto de Geociências, UNICAMP. Campinas, SP. 1995.

RAIMUNDO, S. Nos bananais de Ubatuba (SP): dilemas e desafios para a gestão das unidades de conservação de proteção integral com comunidades tradicionais residentes. São Paulo, Universidade de São Paulo. Dissertação de mestrado. 2001. 168p

As ondas do Litoral Norte (SP): Difusão espacial das práticas caiçaras e do veraneio no Núcleo Picinguaba do Parque Estadual da Serra do Mar (1966-2001). Tese de Doutorado. Instituto de Geociências, UNICAMP. 2007. 